\title{
On the Evolution of Residual Stresses, Microstructure and Cyclic Performance of High-Manganese Austenitic TWIP-Steel after Deep Rolling
}

\author{
Torben Oevermann*, Thomas Wegener and Thomas Niendorf \\ Institute of Materials Engineering, University of Kassel, Moenchebergstraße 3, 34125 Kassel, Germany \\ * Correspondence: oevermann@uni-kassel.de; Tel.: +49-0561-804-3701
}

Received: 14 June 2019; Accepted: 19 July 2019; Published: 25 July 2019

\begin{abstract}
The mechanical properties and the near surface microstructure of the high-manganese twinning-induced plasticity (TWIP) steel $\mathrm{X} 40 \mathrm{MnCrAl19-2}$ have been investigated after deep rolling at high $\left(200^{\circ} \mathrm{C}\right)$, room and cryogenic temperature using different deep rolling forces. Uniaxial tensile tests reveal an increase in yield strength from $400 \mathrm{MPa}$ to $550 \mathrm{MPa}$ due to surface treatment. The fatigue behavior of selected conditions was analyzed and correlated to the prevailing microstructure leading to an increased number of cycles to failure after deep rolling. Deep rolling itself leads to high compressive residual stresses with a stress maximum of about $800 \mathrm{MPa}$ in the subsurface volume characterized by the highest Hertzian pressure and increased hardness up to a distance to the surface of approximately $1 \mathrm{~mm}$ with a maximum hardness of $475 \mathrm{HV} 0.1$. Due to more pronounced plastic deformation, maximum compressive residual stresses are obtained upon high-temperature deep rolling. In contrast, lowest compressive residual stresses prevail after cryogenic deep rolling. Electron backscatter diffraction (EBSD) measurements reveal the development of twins in the near surface area independently of the deep rolling temperature, indicating that the temperature of the high-temperature deep rolling process was too low to prevent twinning. Furthermore, deep rolling at cryogenic temperature leads to a solid-solid phase transformation promoting martensite. This leads to inferior fatigue behavior especially at higher loads caused by premature crack initiation. At relatively low loads, all tested conditions show marginal differences in terms of number of cycles to failure.
\end{abstract}

Keywords: high-manganese steel; deep rolling; TWIP; TRIP; near surface properties; residual stresses; fatigue behavior

\section{Introduction}

In order to meet the high demands of many current applications, e.g., in the mobility sector, not only high-strength materials are required, but also appropriate processes to form components with locally tailored properties. Due to their well balanced properties and low costs, steels are still the material of choice for numerous applications. Since most commercially available steels in general are suffering from a "strength-ductility trade-off", i.e., showing either high strength and limited formability or high ductility and low strength, remarkable effort has been spent on the development of materials overcoming current limitations.

Austenitic metastable high-manganese steels are a representative of advanced high-strength steels with superior mechanical properties, showing high strength combined with excellent ductility, opening up great potentials for new designs in the automotive sector, e.g., relevant for crash-boxes and advanced lightweight components. The balanced combination of high strength and high ductility as well as the generally outstanding properties of high-manganese steels can be attributed to the deformation 
mechanisms being active. Besides dislocation glide, twinning and martensitic transformation can occur leading to two well-known effects: twinning-induced plasticity (TWIP) and transformation-induced plasticity (TRIP). Here, the TRIP-effect is based on a solid-solid phase transformation from austenite to either $\alpha^{\prime}$-martensite or $\epsilon$-martensite. Contribution of each single deformation mechanism can be tailored based on the stacking fault energy (SFE) [1,2]. For instance, a relatively low SFE promotes the martensitic phase transformation, whereas higher values lead to a suppression of this mechanism [3] favoring the formation of mechanical twins or even pure dislocation glide instead [4].

The SFE can on the one hand be influenced by alloying elements. Aluminum, for example, increases the SFE [5], whereas silicon decreases the SFE, supporting the martensitic phase transformation [6]. On the other hand, high strain rate deformation increases the SFE in face-centered cubic alloys, as shown by Fiarro et al. [7]. Another way to tailor the SFE, which can be easily integrated into a process, is to decrease or increase the temperature of the material during deformation. As a result, the different deformation mechanisms can be activated as a function of the deformation temperature for a material with a given chemical composition. This was shown, e.g., by Rüsing et al. [8] investigating the effect of pre-deformation temperature on the fatigue behavior of the high-manganese austenitic steel X40MnCrAl19-2. In that study, twinning was observed upon deformation at room temperature, whereas, in addition to twinning, $\epsilon$ - as well as $\alpha^{\prime}$-martensite could be detected after pre-straining at $-196^{\circ} \mathrm{C}$. Following deformation at a temperature of $400^{\circ} \mathrm{C}$, twinning and phase transformation could not be seen.

The fatigue behavior of high-manganese steels in different regimes, i.e., low-cycle and high-cycle fatigue (LCF/HCF) regimes as well as the crack growth regime were investigated and reported in numerous studies. Schilke et al. [9] studied the LCF behavior of austenitic medium-manganese steels with a manganese content of $12-13 \mathrm{wt} \%$ in rolled and as-cast conditions revealing initial cyclic hardening, in line with the monotonic behavior, followed by cyclic softening. This is in good agreement with the findings of $\mathrm{Wu}$ et al. [10], who investigated the cyclic deformation response and deformation mechanisms of a TWIP steel in the LCF regime. They observed twinning and the formation of persistent slip bands providing for a strong work hardening effect. Another LCF study for TRIP/TWIP steels with varying carbon contents was conducted by Shao et al. [11]. In addition to the already mentioned initial cyclic hardening, they observed a more pronounced hardening with an increasing strain amplitude. Another study of the same group focusing on the effect of grain size on the cyclic deformation response in the LCF regime revealed three characteristic stages of the stress response [12]. An initial cyclic hardening attributed to intense dislocation interaction was followed by a stage of cyclic softening caused by a rearrangement of dislocations. The softening was followed by a second cyclic hardening stage related to the formation of a particular dislocation structure. Moreover, the results showed superior LCF properties upon grain refinement.

Similar results on the effect of grain size on the cyclic deformation response of the X-IP $\mathrm{IM}_{1000}$ TWIP steel were reported by Rüsing et al. [13]. Compared to fine grained material, lower stress amplitudes for given strain amplitudes as well as a more pronounced cyclic softening at medium to high strain amplitudes were found for the coarse grained condition and attributed to a rearrangement of dislocations. The effects of phase transformation on the LCF behavior of austenitic high-manganese steels have been analyzed by Ju et al. [14] and Nikulin et al. [15]. The first study reported on fatigue crack propagation along the $\gamma / \epsilon$ interface focusing on short cracks. Dependent on the actual alloying composition, the formation of $\epsilon$-martensite either contributed to a decrease of fatigue crack growth rates due to crack tip distortion or increased crack growth rates due to phase transformation promoted embrittlement. These results are in good agreement with the investigations of Nikulin et al. focusing on the effect of $\gamma \rightarrow \epsilon$-martensitic phase transformation on the LCF behavior and the fatigue induced microstructure of Fe-Mn-Cr-Ni-Si alloys. They showed that, as a function of varying Si contents, the $\epsilon$-martensite formation can either improve or deteriorate fatigue resistance of this alloy. Martensite stability was found to be the key, while fatigue crack advance within the $\epsilon$-martensite was strongly affected. Pathways towards improvement of LCF properties of high-manganese steels were reported 
by Niendorf et al. [16] and Guo et al. [17], both applying pre-deformation. Niendorf et al. showed that monotonic pre-straining of the X-IP ${ }^{\mathrm{TM}} 1000$ TWIP steel up to $20 \%$ led to impeded dislocation mobility due to an increased density of twins acting as effective barriers against dislocation glide. Eventually, this led to a stable cyclic deformation response (CDR) with significantly improved fatigue lives. These results are in excellent agreement with the investigations of Guo et al. on a Fe- $17 \mathrm{Mn}-0.8 \mathrm{C}$ steel. In addition to pre-deformation in tension, drawing was carried out. In case of the stretched samples, the CDR was stabilized, resulting in increased fatigue lives. For the pre-drawn condition, the fatigue life in the LCF was further enhanced. This was attributed to a more effective grain refinement as well as multi-variant twins formed by drawing.

Hamada et al. [18,19] conducted HCF experiments on four different high-manganese TWIP steels in reverse plane bending. Despite the different chemical compositions, a fatigue limit of $400 \mathrm{MPa}$ was reported. Ratios of fatigue limit and tensile strength were varying between 0.42 and 0.48 . Mechanical twins were not formed during cyclic loading; however, planar slip bands formed during the early stages of deformation. These were found to induce micro-cracks by interactions with grain boundaries and annealing twins. Another study of the same group [20] focused on enhancing HCF properties by grain refinement. Imposed by cold-rolling and recrystallization annealing, for the high-manganese Fe-22Mn-0.6C steel an average grain size of $1.8 \mu \mathrm{m}$ could be obtained, while the coarse grained (CG) material was characterized by an average grain size of $35 \mu \mathrm{m}$. Upon grain refinement, the fatigue limit as well as the ratio of the fatigue limit to the ultimate tensile strength were increased from $400 \mathrm{MPa}$ to $560 \mathrm{MPa}$ and from 0.46 to 0.50 , respectively. Despite the ultra-fine grained microstructure, the activity of deformation mechanisms during cyclic deformation was found to be similar to the CG counterpart. Likewise, Song et al. [21] reported on enhanced HCF properties for cold-drawn Fe-Mn-C TWIP steels. Cold-drawing up to a strain of $\epsilon=0.45$ resulted in a maximum fatigue strength of $875 \mathrm{MPa}$, a subsequent stress relieving annealing for two hours at $400^{\circ} \mathrm{C}$ increased the fatigue strength to even $975 \mathrm{MPa}$. The improvement upon heat-treatment was related to a relief of dislocation pile-ups alongside grain boundaries. In line with the results reported for the X-IP ${ }^{\mathrm{TM}} 1000$ TWIP steel in the LCF regime, Niendorf et al. [22] showed that, in case of loading in the HCF regime, superior properties are obtained upon relatively high pre-strain levels of $40 \%$. Most recent results on improvement of HCF properties of high-manganese steels were reported by Shao et al. [23,24]. In one study, a gradient microstructure in the surface layer of a high-manganese TWIP steel was achieved by a novel surface treatment process named surface spinning strengthening (3S). Due to this treatment, a hardened layer with a thickness of about $1 \mathrm{~mm}$, accompanied by a grain size gradient, was established. As a result, the fatigue limit of the $3 S$ samples increased by about $26 \%$ compared to their as-received counterparts. This enhancement was mainly attributed to the suppression of fatigue crack initiation. In a second study of the same group, a linear gradient in grain size was established in an Fe-30Mn-0.6C TWIP steel sample by pre-torsion and annealing ( $T \& A$ treatment). The graded sample exceeded the fatigue strength of both the coarse-grained as well as the fine-grained structure. The superior properties of the microstructurally graded material in the HCF regime were ascribed to a pronounced generation of dislocations and the formation of a hard core and soft shell during cyclic loading.

Generally, the fatigue behavior of a material is significantly influenced by its surface condition, i.e., the near surface microstructure, roughness, phase fractions and the distribution of residual stresses [25-27]. The surface condition can be enhanced by different types of surface treatments like attrition, turning, deep rolling or shot-peening. For metastable austenitic stainless steels, numerous studies are available in a literature reporting on the influence of the aforementioned treatments. These were applied to modify the surface layer by introducing mechanical twins, martensite, compressive residual stresses and/or increased dislocation density. The improvement of fatigue properties by the generation of compressive residual stresses in the surface layer has been discussed in detail, e.g., in [28]. Nevertheless, currently only limited data reporting on the influence of residual stresses on the fatigue behavior of high-manganese TWIP/TRIP steel are available. Teichmann et al. [29] investigated the effect of shot-peening on the mechanical properties of a high-manganese TWIP steel. 
As a result of shot-peening with an intensity of $0.30 \mathrm{mmA}$, compressive residual stresses reached a maximum of $1400 \mathrm{MPa}$. Moreover, the fatigue strength in rotation bending testing was increased from 400 to $600 \mathrm{MPa}$ for the shot-peened condition. Another study from Klein et al. [30] focused on the surface morphology and its influence on the cyclic deformation behavior of a commercial TWIP steel. Phase fractions as well as residual stresses were determined for the as-received, an upand down-milled and a polished reference condition. Compressive residual stresses were found for each condition investigated, revealing a maximum value of $800 \mathrm{MPa}$ for the up-milled surface. In the LCF regime, fatigue life was mainly influenced by the surface topography resulting in the lowest number of cycles to failure for the as-received condition due to its high roughness. Improved fatigue life was found for the polished condition. However, the cyclic deformation response in the HCF regime was significantly influenced by other surface features, i.e., residual stresses and nano-crystalline sub-surface layers, respectively. Consequently, the best performance in the HCF regime was reported for the up-milled condition being characterized by highest compressive residual stresses and a nano-crystalline surface layer.

Deep rolling at different temperatures is particularly suitable to simultaneously tailor local plastic deformation and the global SFE of the material treated. The process allows for high plastic deformation of the near surface layer and can be conducted at very low or very high temperatures. Moreover, deep rolling is a mechanical surface treatment that is known for smoothing the surface, inducing high compressive residual stresses and providing a significant amount of work hardening, reported in several studies, e.g., in [27,31-33]. The changes within the surface layer strongly improve the fatigue life and, thus, are of highest importance for the material behaviour under cyclic loading. Based on the experiments conducted, the present paper reports on the performance of the high-manganese TWIP steel X40MnCrAl19-2 after deep rolling at various temperatures ( $-196^{\circ} \mathrm{C}$, room temperature, $\left.200^{\circ} \mathrm{C}\right)$. The following novel insights into process-microstructure-property relationships in TWIP steels will be presented:

- Evolution of the microstructure dependent on the deep rolling temperature affected by the different activated elementary deformation mechanisms upon surface treatment.

- Development of residual stresses dependent on the deep rolling temperature.

- Improvement of the cyclic deformation behavior imposed by microstructure and residual stress state.

\section{Materials and Methods}

The material studied in the present work is the high-manganese austenitic steel X40MnCrAl19-2 (precidur ${ }^{\circledR}$ H-Mn LY) provided by thyssenkrupp Hohenlimburg GmbH (Hagen, Germany). The chemical composition is given in Table 1. The electron backscatter diffraction (EBSD) micrograph shown in Figure 1 reveals the presence of recrystallization twins in the homogenous as-received microstructure being characterized by an average grain size of about $20 \mu \mathrm{m}$. The material was provided as hot-rolled blank with a thickness of $9 \mathrm{~mm}$. Cylindrical specimens were machined by turning. Before, cuboid specimens of about $9 \mathrm{~mm} \times 121 \mathrm{~mm} \times$ sheet thickness were obtained by water jet cutting with the longitudinal axis of all specimens being perpendicular to the rolling direction of the sheet. The final specimen geometry is shown in Figure 2. Tensile testing of the untreated condition at room temperature revealed a relatively low yield strength of about $400 \mathrm{MPa}$, an ultimate tensile strength of $880 \mathrm{MPa}$ and an elongation to fracture of $52 \%$ (see Figure 3). The mechanical properties are similar to those determined by Rüsing [34], who also performed tensile tests at elevated and cryogenic temperatures, showing that the material is characterized by higher tensile strength at cryogenic temperature, and an increase of the yield strength by a factor of two. The average hardness of the as-received material was found to be $250 \mathrm{HV}$. 
Table 1. Chemical composition of the austenitic TWIP steel X40MnCrAl19-2 (Fe: Bal).

\begin{tabular}{|c|c|c|c|c|c|}
\hline $\begin{array}{c}\mathrm{C} \\
\mathrm{Wt} . \%\end{array}$ & $\begin{array}{c}\text { Si } \\
\text { Wt. } \%\end{array}$ & $\begin{array}{c}\text { Mn } \\
\text { Wt. } \%\end{array}$ & $\begin{array}{c}P \\
\text { Wt. } \%\end{array}$ & $\begin{array}{c}\text { S } \\
\text { Wt. } \%\end{array}$ & $\begin{array}{c}\text { Al } \\
\text { Wt. } \%\end{array}$ \\
\hline 0.45 & 0.40 & 20.00 & 0.03 & 0.005 & 2.50 \\
\hline $\begin{array}{c}\mathrm{Cr} \\
\text { Wt. } \%\end{array}$ & $\begin{array}{c}\mathrm{Cu} \\
\mathrm{Wt} . \%\end{array}$ & $\begin{array}{c}\text { V } \\
\text { Wt. } \%\end{array}$ & $\begin{array}{c}\text { Mo } \\
\text { Wt. } \%\end{array}$ & $\begin{array}{c}\text { Ti } \\
\text { Wt. } \%\end{array}$ & $\begin{array}{c}\mathrm{Ni} \\
\mathrm{Wt} . \%\end{array}$ \\
\hline 2.50 & 0.20 & 0.20 & 0.20 & 0.20 & 1.00 \\
\hline
\end{tabular}

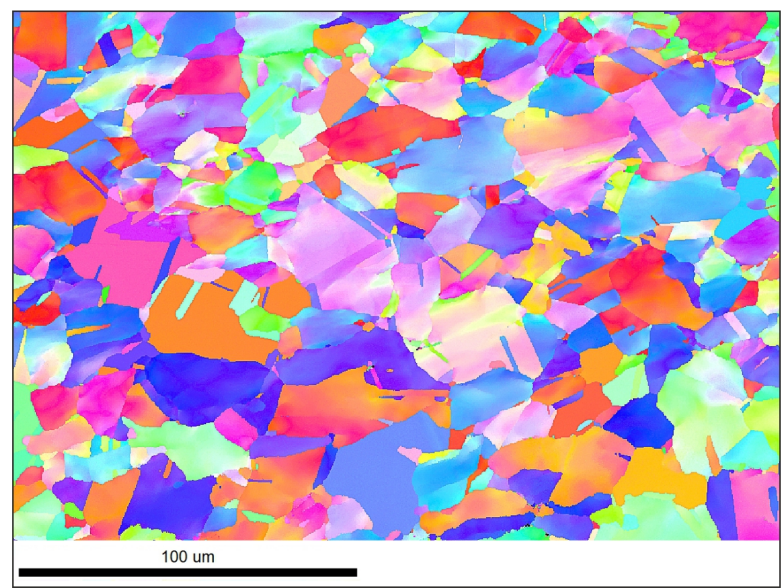

Figure 1. Inverse Pole Figure (IPF) map of the as-received condition showing a homogenous microstructure with recrystallization twins and an average grain size of about $20 \mu \mathrm{m}$.

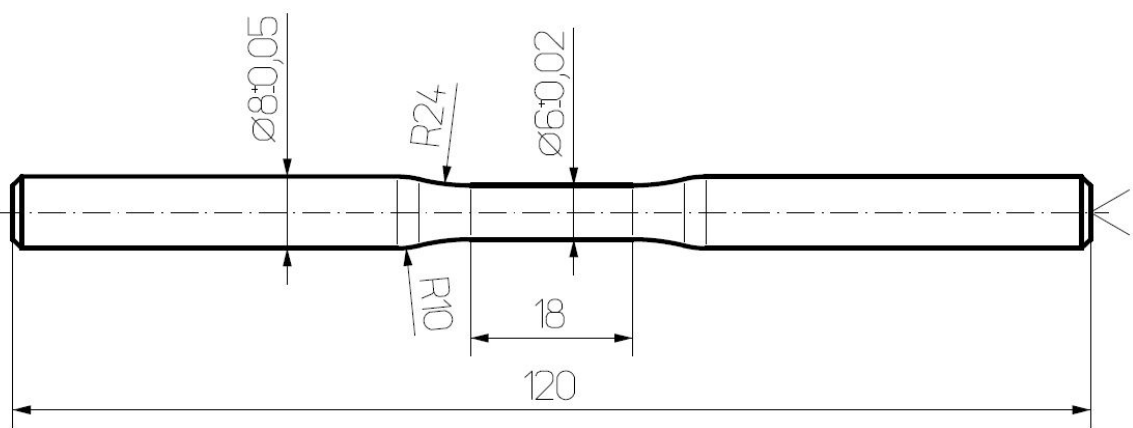

Figure 2. Specimen geometry employed for tensile and fatigue tests, units in millimeters.

To manufacture specimens with different surface properties, the turned specimens were deep rolled using different process parameters under controlled conditions on a servo-conventional lathe of type Weiler C30 (Weiler Werkzeugmaschinen $\mathrm{GmbH}$, Emskirchen, Germany). In preliminary studies, the deep rolling force was varied to analyze its influence on the near surface hardness and residual stress depth profiles to obtain adequate surface properties for further investigations. With respect to the obtained results (see Figure 4) and to avoid bending of the specimens during the deep rolling process at even higher forces, a deep rolling force of $855 \mathrm{~N}$ was chosen. The deep rolling force was applied by a one-roller tool made by Ecoroll (Celle, Germany) with a diameter of $\varnothing 40 \mathrm{~mm}$. A constant feed rate of $1 \mathrm{~mm}$ per revolution at a rotational speed of $80 \mathrm{rev}$. $/ \mathrm{min}$ was applied. Deep rolling was carried out at room, cryogenic $\left(-196^{\circ} \mathrm{C}\right)$ and high temperature $\left(200^{\circ} \mathrm{C}\right)$. Cryogenic deep rolling was performed using liquid nitrogen employing a custom-built device. High-temperature deep rolling was carried out using an induction heater (TRUMPF Hüttinger GmbH, Freiburg, Germany) controlled by a pyrometer (Sensortherm GmbH, Sulzbach, Germany). 


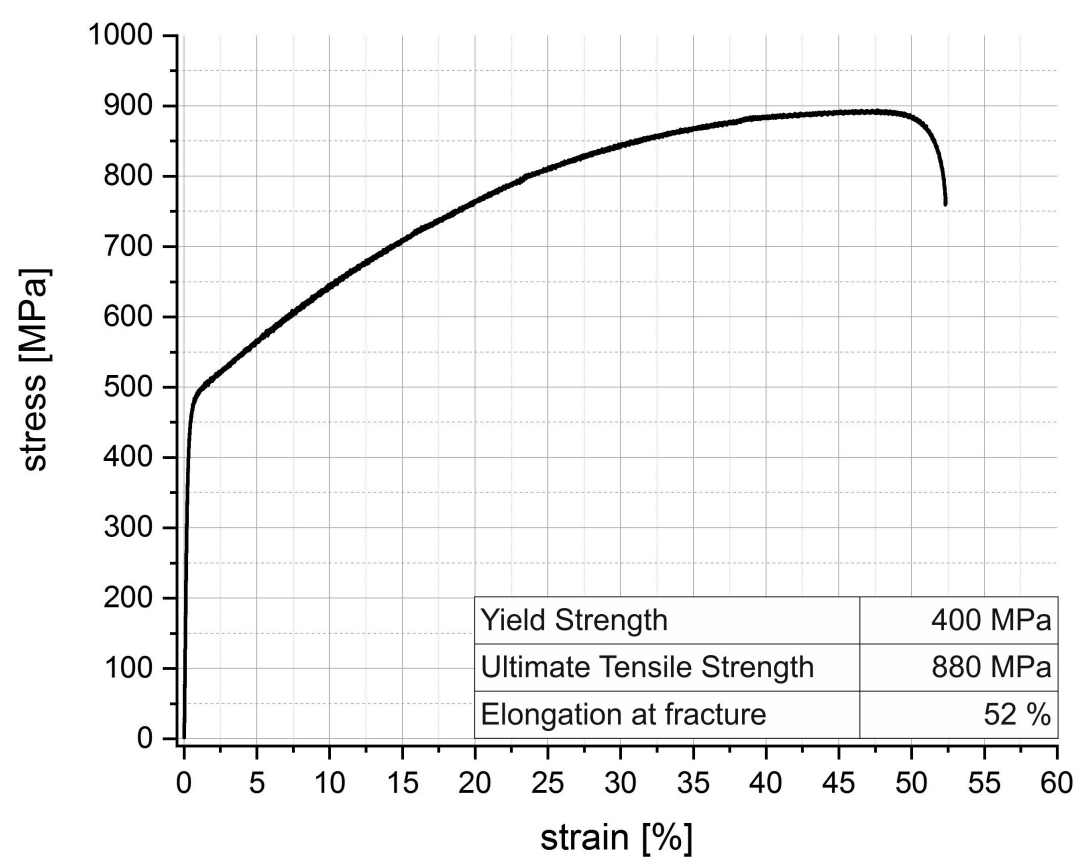

Figure 3. Stress-strain diagram for the as-received twinning-induced plasticity (TWIP) steel tested at room temperature. The inset summarizes the most important characteristic values.

a)

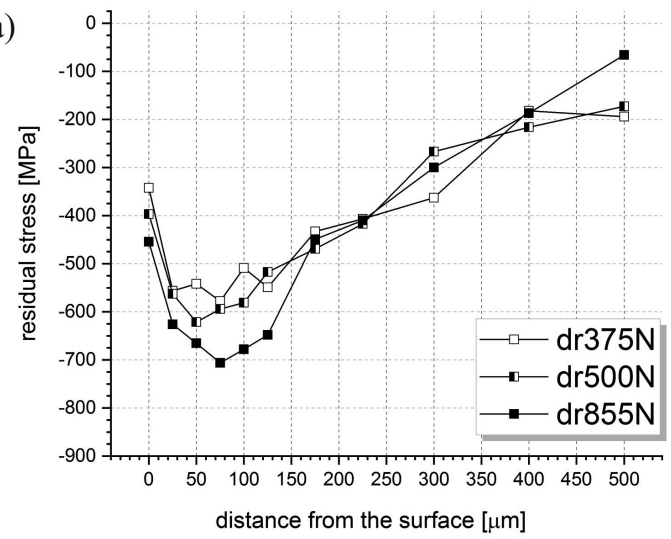

b)

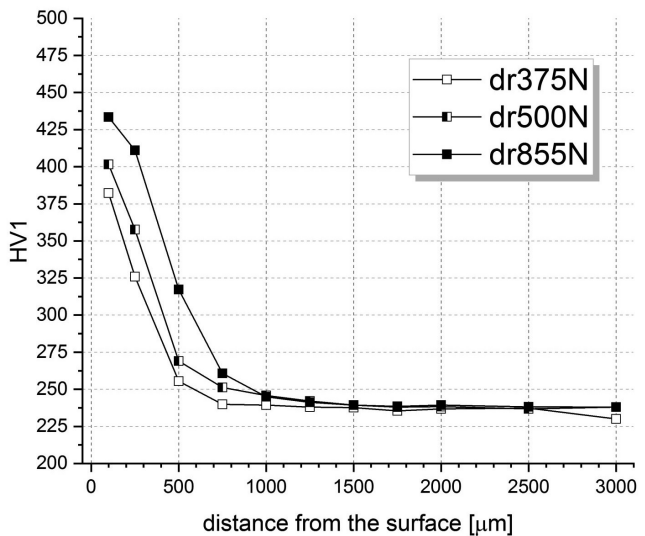

Figure 4. Residual stress depth profiles in longitudinal direction (a) and near-surface hardness distribution (b) after deep rolling at room temperature applying deep rolling forces between $375 \mathrm{~N}$ and $855 \mathrm{~N}$.

After deep rolling, the near surface properties were characterized. Vickers hardness measurements were carried out on polished cross sections to determine the overall hardness distribution and the increase of hardness in the near surface area induced by the surface treatment process. The measurements were conducted using a Struers DuraScan-70 system (Hannover, Germany) employing loads of $9.81 \mathrm{~N}$ and $1.96 \mathrm{~N}$, respectively. Microstructure analysis, focusing on mechanical twinning and strain induced phase transformation in the surface layer, was conducted using a Zeiss ULTRA GEMINI high-resolution scanning electron microscope (SEM) (Jena, Germany) at an acceleration voltage of $30 \mathrm{kV}$. The SEM employed is equipped with an EBSD unit and a back scattered electron (BSE) detector. A second SEM system (CamScan MV 2300, Tescan GmbH, Dortmund, Germany) operated at $20 \mathrm{kV}$ was used to carry out fracture surface investigations for representative fatigued specimens. For EBSD characterization, cross sections of the specimens were mechanically ground down to $5 \mu \mathrm{m}$ grit size using $\mathrm{SiC}$ paper and polished using a diamond suspension to a 
minimum of $1 \mu \mathrm{m}$. The final step of the polishing process was vibration polishing for 16 hours using conventional oxide polishing suspension (OPS) $(0.04 \mu \mathrm{m})$.

Residual stress depth profiles and integral width values were analyzed by $\mathrm{X}$-ray diffraction (XRD) using a HUBER-diffractometer (Huber Diffraktionstechnik GmbH, Rimsting, Germany) equipped with a $1 \mathrm{~mm}$ collimator. The $\{220\}$-planes of the austenitic phase were considered at a $2 \theta$ angle of $128.78^{\circ}$ using $\mathrm{CrK} \alpha$-radiation. To analyze stress profiles in depth, surface layers were removed layerwise by electro-chemical polishing. All values obtained were evaluated utilizing the standard $\sin ^{2} \Psi$-method $\left(\frac{1}{2} s_{2}=6,75 E^{-6} \mathrm{~mm}^{2} \mathrm{~N}^{-1}\right)$ not considering any mathematical stress correction. In addition, phase analysis was performed by XRD.

To determine the influence of the different deep rolling parameters on the mechanical behavior, monotonic tensile and stress controlled fatigue tests in the HCF regime were performed using a digitally controlled servo-hydraulic test rig equipped with a $63 \mathrm{kN}$ load cell. Monotonic stress-strain diagrams were plotted based on strains calculated based on crosshead displacement taking into account the nominal specimen gauge length of $18 \mathrm{~mm}$ (cf. Figure 5). The uniaxial tensile tests were performed under displacement control with a constant crosshead speed of $2 \mathrm{~mm} / \mathrm{min}$. The HCF tests were carried out in stress control under fully reversed push-pull loading with a stress ratio of $R=-1$. For strain measurement, an extensometer featuring a gauge length of $12 \mathrm{~mm}$, directly attached to the surface of the specimens, was used. To avoid heating of the specimens, compressed air cooling was used. Specimen temperature was limited to a maximum of $30^{\circ} \mathrm{C}$. The standard frequency for the $\mathrm{HCF}$ tests was $15 \mathrm{~Hz}$, however, had to be reduced to $1 \mathrm{~Hz}$ at loads above $400 \mathrm{MPa}$. For all load levels, an adequate number of specimens was considered; however, no statistical evaluation was carried out. Representative fracture surfaces were chosen for examination using the SEM mentioned above.

\section{Results and Discussion}

\subsection{Characterization of the Near Surface Properties}

As expected, the deep rolling process leads to increased hardness in the near surface area. The hardness values presented in Figure $4 \mathrm{~b}$ highlight the relationship between the applied deep rolling force and the degree of cold hardening. For all conditions, the maximum hardness is always obtained at the surface. The lowest applied deep rolling force of $375 \mathrm{~N}$ increases the hardness in a depth of $0.15 \mathrm{~mm}$ to a maximum of about $400 \mathrm{HV}$. Higher deep rolling forces lead to an even more pronounced cold hardening effect with hardness values increased by a factor of 1.65 and 1.75 , respectively, compared to the hardness of the as-received state. In line with the relations in terms of the maximum hardness, the in-depth effect imposed by the surface treatment increases with increasing deep rolling force. The lowest deep rolling force applied leads to increased hardness values up to a depth of $0.6 \mathrm{~mm}$ compared to $0.9 \mathrm{~mm}$ for the highest deep rolling force. This is in good agreement with the results of Teichmann et al. [29] reporting on the influence of shot peening on the mechanical behavior of a different TWIP steel grade. Compared to a hardness of $250 \mathrm{HV} 0.1$ in the as-received condition, a maximum hardness of $550 \mathrm{HV} 0.1$ was observed after shot peening with the highest Almen intensity of $0.3 \mathrm{mmA}$. Concomitantly, a higher penetration depth was found with increasing peening intensity. The saturation seen for shot peening could not be observed for the deep rolling parameters applied in the present study. Nevertheless, maximum hardness was shown for the highest peening intensity [29]. Comparing the two surface treatment processes in terms of hardness evolution, it can be revealed that the depth effect for deep-rolling is almost 4 to 5 times higher than in the case of shot peening.

Results obtained by residual stress measurements, plotted for longitudinal direction, are presented in Figure 4a. Compared to the hardness distribution (Figure 4b), discussed above, a similar trend can be observed. Regardless of the process parameters, compressive residual stresses are generated. The maximum values are always seen in direct vicinity of the surface, i.e., located at a distance to the surface of about $50 \mu \mathrm{m}$ to $100 \mu \mathrm{m}$. This depth can be related to the area of the highest Hertzian 
pressure during deep rolling. In general, a higher deep rolling force results in higher residual stress values at the surface. However, for all conditions, the values at distances to the surface above $175 \mu \mathrm{m}$ are found to be almost identical. In contrast to the results from hardness measurements, the analysis of residual stress distribution presented by Teichmann et al. [29] for the shot peened TWIP steel reveals some differences compared to present results. While penetration depth increases with higher shot intensities, the residual stress maxima reveal a different behavior. After an intensity increase from 0.15 to $0.22 \mathrm{mmA}$, hardly any changes are seen in residual stress maxima; however, a further increase to $0.30 \mathrm{mmA}$ results in a significant increase of compressive stresses to $1400 \mathrm{MPa}$. This different behavior can be rationalized based on the characteristics of both surface treatment processes. While for deep rolling the force exerted to the specimen is concentrated in one single contact zone, the effective force imposed by shot peening is distributed in a contact zone area.

Tensile testing reveals that deep rolling at room temperature leads to an increased strength. From Figure 5, it can be seen that the yield strength, in many studies stated to be a roadblock towards use of high-manganese steels [35], is increased by the deep rolling process, i.e., from $400 \mathrm{MPa}$ in the untreated condition to $550 \mathrm{MPa}$. Furthermore, a minor increase of the ultimate tensile strength to a maximum value of $940 \mathrm{MPa}$ is seen, whereas the elongation to fracture remains stable at about $50 \%$. Using different deep rolling temperatures, the monotonic mechanical properties are affected similarly, cf. Figure 5 .
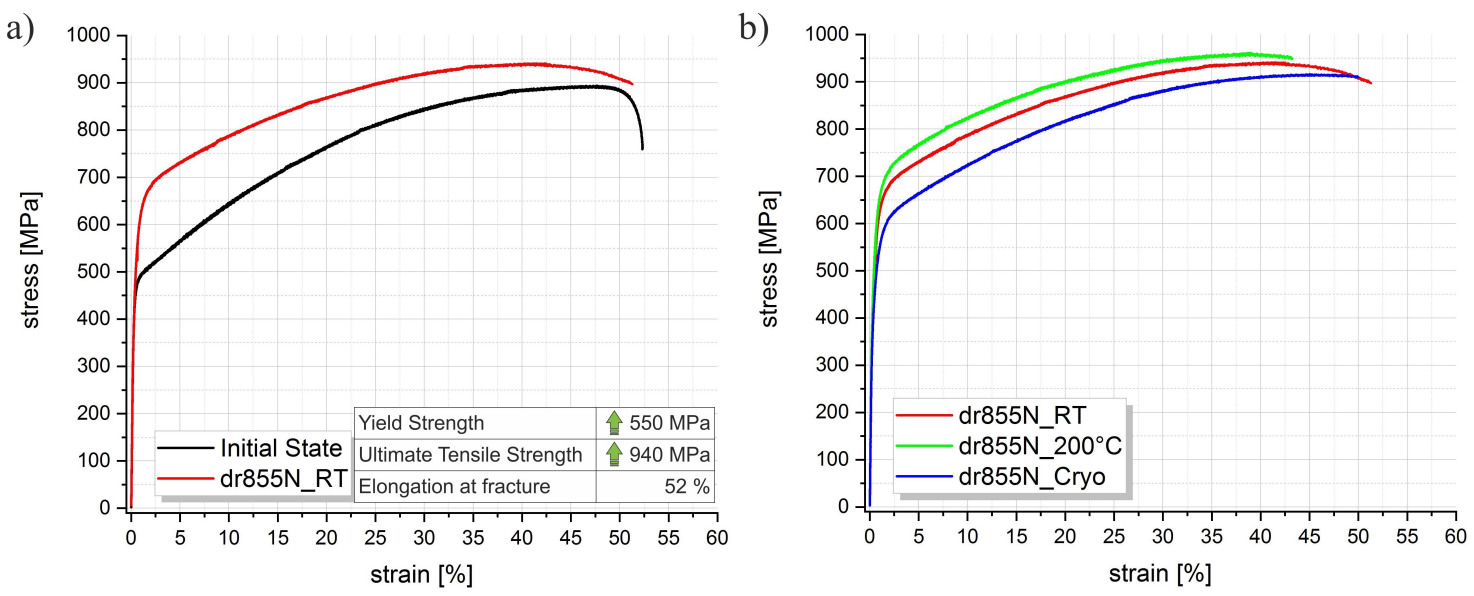

Figure 5. Monotonic stress-strain response of the as-received material compared to a specimen deep rolled at room temperature using a deep rolling force of $855 \mathrm{~N}$ (a) and direct comparison of the conditions deep rolled at different temperatures applying the same deep rolling force $(\mathbf{b})$.

Figure 6 shows representative micrographs obtained by EBSD for the three deep rolled conditions characterized in the present study, i.e., the (a) room temperature, (b) $200^{\circ} \mathrm{C}$ and (c) cryogenic temperature deep rolled specimens. The step size for all EBSD maps shown was $1 \mu \mathrm{m}$. A very similar homogeneous microstructure, as shown for the as-received condition in Figure 1, can be seen (with respect to grain size and texture) for all conditions. Considering the room temperature deep rolled condition in detail, some grains featuring mechanical twins can be made out. The majority of these twins is located in a distance to the surface of about $100 \mu \mathrm{m}$, which can be related to the area of the highest Hertzian pressure during the deep rolling process as already mentioned above. Phase transformation (corresponding phase maps are not shown for sake of brevity) from the austenitic $\gamma$-phase to either $\epsilon$ - or $\alpha^{\prime}$-martensite could not be detected as a result of deep rolling at room temperature. From these findings it can be deduced that, due to the high SFE at room temperature, the austenite grains were mainly deformed by mechanical twinning and dislocation glide. This behavior is consistent with current literature. A very similar microstructure revealing grains with abundant mechanical twins and even formation of secondary and double twins was reported by Song et al. [21] for a Fe-Mn-C TWIP steel upon drawing at room temperature. Furthermore, 
Rüsing et al. [8] found numerous twins, stacking faults and a high density of dislocations using transmission electron microscopy (TEM) in the material investigated in the current study as a result of room temperature tensile deformation to an elongation of 50\%. The EBSD micrograph of the specimen deep rolled at $200{ }^{\circ} \mathrm{C}$ shown in Figure $6 \mathrm{~b}$ is characterized by a very similar microstructure as compared to the room temperature deep rolled condition displayed in (a). Again, mechanical twins can be observed in several grains in the area being characterized by the highest Hertzian pressure, whereas no phase transformation was detected. Both martensitic transformation and twinning cannot be seen after stretching at a significantly higher deformation temperature of $400{ }^{\circ} \mathrm{C}$ in the study of Rüsing et al. [8]. From these findings, it can be deduced that a deep rolling temperature of $200^{\circ} \mathrm{C}$ is not high enough to suppress twinning. With respect to the prevailing deformation mechanisms and resulting microstructure evolution, a different behavior can be seen for the condition deep rolled at cryogenic temperature displayed in Figure 6c. Deformation induced phase transformation seems to be the dominant deformation mechanism for this condition. This is confirmed by the phase distribution map displayed in Figure $6 \mathrm{~d}$ where large areas are indexed as hexagonal $\epsilon$-martensite. In line with the deep rolled conditions at $200{ }^{\circ} \mathrm{C}$ and room temperature, the largest fraction of $\epsilon$-martensite is detected in a distance to the surface of approximately $100 \mu \mathrm{m}$, again being rationalized by the highest Hertzian pressure. These results are once more consistent with findings of Rüsing et al. [8], showing fractions of $\epsilon$-martensite as well as $\alpha^{\prime}$-martensite in addition to twins for a specimen deformed in tension to an elongation of $40 \%$ at a temperature of $-196^{\circ} \mathrm{C}$. The absence of $\alpha^{\prime}$-martensite in the deep rolled condition of the current study is thought to be due to the different loading situation in deep rolling as compared to tensile testing.

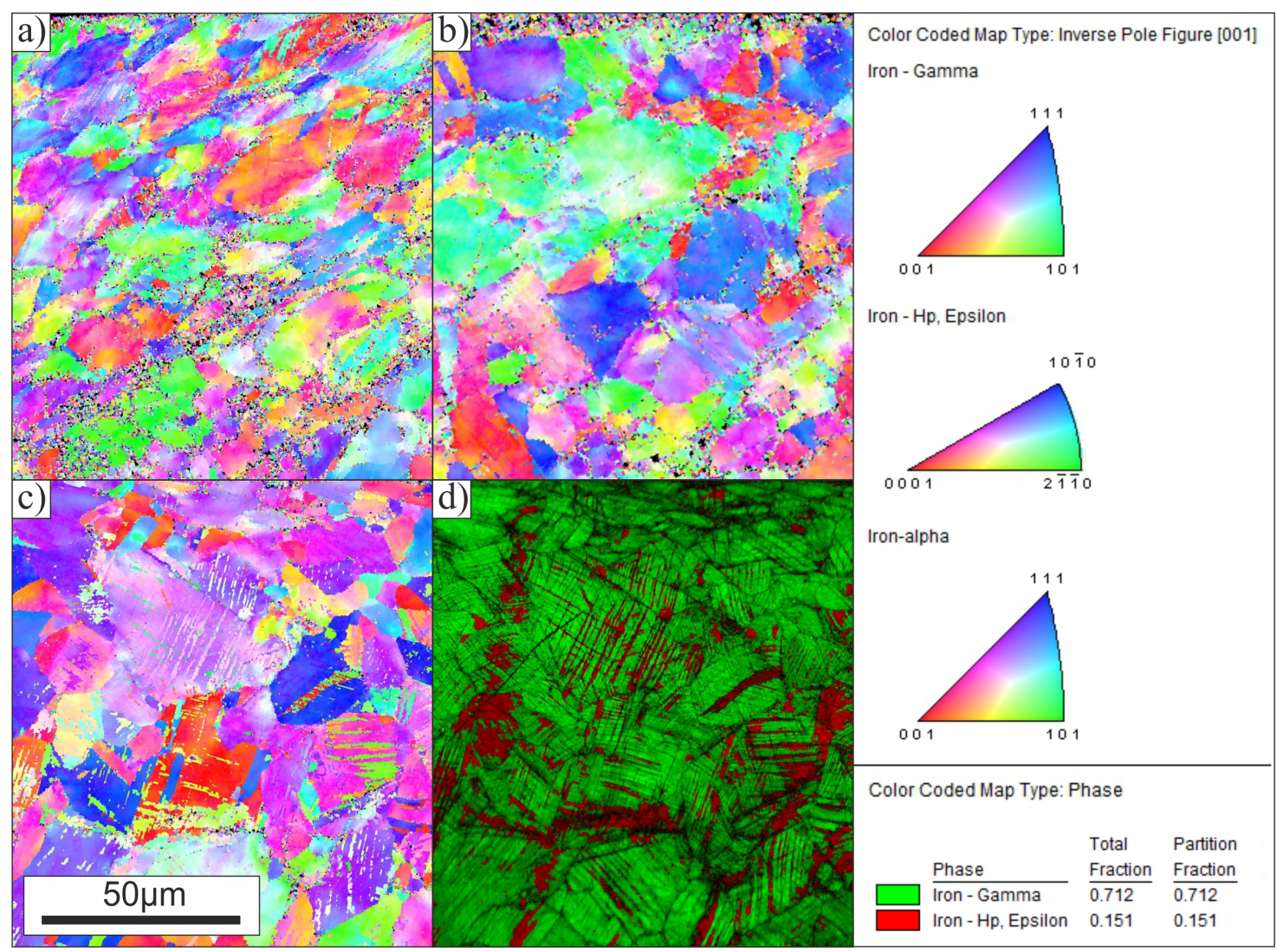

Figure 6. IPF maps $(\mathbf{a}-\mathbf{c})$ and phase map with superimposed image quality (IQ) (d) for differently treated specimens. IPF maps depict the near surface microstructure following deep rolling at room temperature (a), $200{ }^{\circ} \mathrm{C}(\mathbf{b})$ and cryogenic temperature (c) using a deep rolling force of $855 \mathrm{~N}$. The IQ-phase map for a surface layer after deep rolling at cryogenic temperature is shown in (d). What appears to be twinning in the IPF map clearly is resolved as a $\gamma \rightarrow \epsilon$ phase transformation in (d). Color coding in (a-d) is in accordance to the standard triangles and the nomenclature shown to the right. 
Focusing on the mechanical properties of the surface layer, both the degree of work hardening and the affected depth can be tailored by changing the temperature of the deep rolling process, cf. Figure 7. Increasing the temperature to $200{ }^{\circ} \mathrm{C}$ leads to generally increased hardness values throughout the probed volume with a maximum hardness of $460 \mathrm{HV}$ near the surface and increased hardness values up to a depth of $1.0 \mathrm{~mm}$. On the contrary, as a result of decreasing the deep rolling temperature to $-196^{\circ} \mathrm{C}$ by using liquid nitrogen, local plastic deformation seems to be impeded, leading to a minor increase of the hardness. In order to compare hardness and work hardening of the different conditions, it has to be considered that the deep rolling force was constant, while the temperature varied between $-196^{\circ} \mathrm{C}$ and $200^{\circ} \mathrm{C}$. Since a decreasing temperature leads to differences in mechanical properties (higher yield strength and ultimate tensile strength) as seen in tensile tests conducted by Rüsing [34], here a constant load results in less pronounced work hardening as the resistance of the material against plastic deformation increases. At high temperatures, the opposite effect is achieved. Even if martensitic transformation is seen in the specimens deep rolled at cryogenic temperature, hardness is lower as compared to the other two conditions. Further work including varying deep rolling forces at given temperatures will have to be conducted for an in-depth evaluation of evolving microstructural features and related local hardness. This, however, is beyond the scope of the current work.

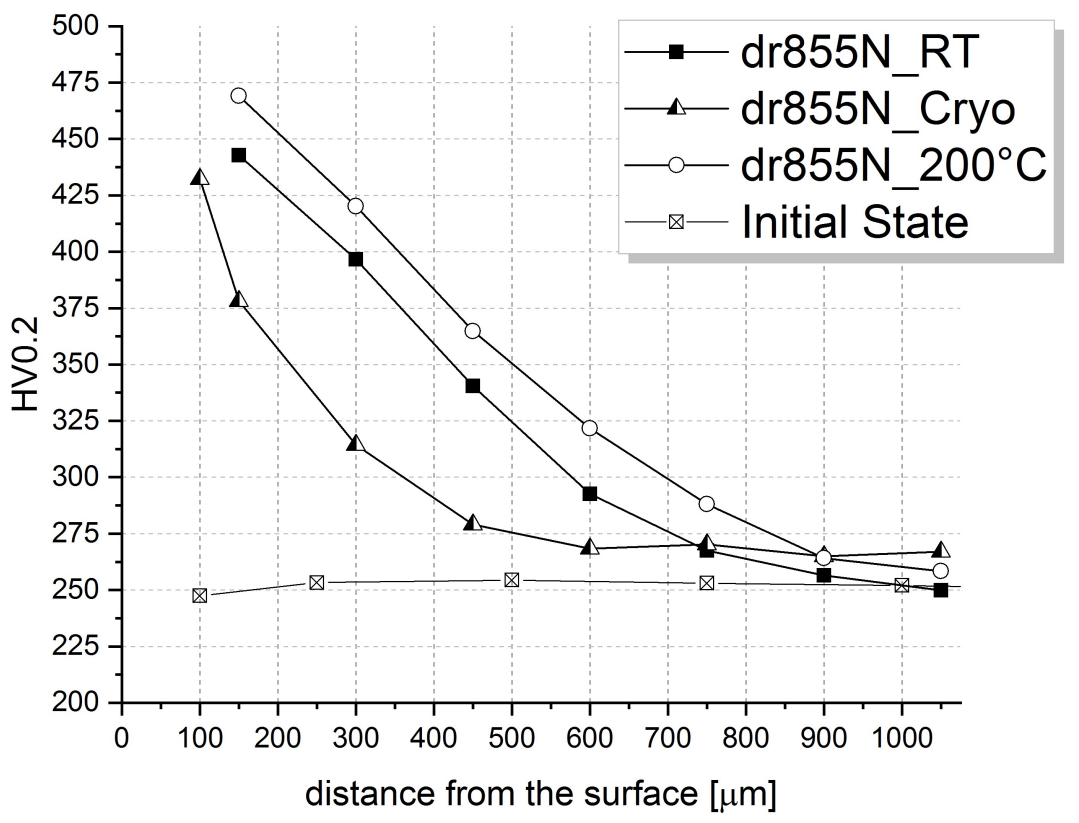

Figure 7. Hardness distribution in the near surface area after deep rolling in a temperature range from $-196^{\circ} \mathrm{C}$ (Cryo) to $200^{\circ} \mathrm{C}$ at a constant deep rolling force of $855 \mathrm{~N}$.

In line with the hardness measurements, the remarkable influence of process temperature on the development of residual stresses is revealed by the results presented in Figure 8. Deep rolling at $200^{\circ} \mathrm{C}$ strongly promotes the evolution of compressive residual stresses, leading to a maximum of about $840 \mathrm{MPa}$ at a distance to the surface of $75 \mu \mathrm{m}$ compared to only $700 \mathrm{MPa}$ after deep rolling at room temperature determined in the same depth (results for longitudinal direction). Clearly, the effect of deep rolling temperature is much more pronounced as compared to the effect of deep rolling force. The residual stress depth profile maxima for the measurements in circumferential direction are slightly shifted towards the core of the specimens and a lower absolute value of the compressive residual stresses can be observed here. The integral width values for austenitic steels after surface treatment are expected to be characterized by maximum values at the surface and a small plateau in the area of the highest Hertzian pressure, as has been shown in [27].

All residual stress measurements were performed solely considering the austenitic phase of the material. Rüsing et al. reported in [8] that a martensitic phase transformation to either $\alpha^{\prime}$-martensite 
or $\epsilon$-martensite has to be expected after plastic deformation at cryogenic temperature for the TWIP steel considered. This observation was also confirmed by phase analysis using EBSD (cf. Figure 6c,d). In order to provide for better statistics, XRD phase analysis was carried out in parallel to every step of the residual stress profile determination, i.e., on the same spot used for stress determination in longitudinal direction. The qualitative results of the measurement are shown in Figure 9. The 3D-plot depicted clearly reveals that the maximum $\epsilon$-martensite phase fraction is present at a distance of about $0.075 \mathrm{~mm}$ to $0.125 \mathrm{~mm}$ from the surface. Compared to the residual stress depth profile (Figure 8 ) in the longitudinal direction, this is apparently the area undergoing the highest Hertzian pressure during the deep rolling process [36]. After the $\epsilon$-martensite phase fraction reaches its maximum, the amount decreases constantly. The intensity of both austenitic peaks shows no clear trends. This is attributed to the relatively coarse austenite grains. Consequently, results will not be further interpreted. X-ray diffraction peaks used for determination of residual stresses are shown in Figure 10.

a)

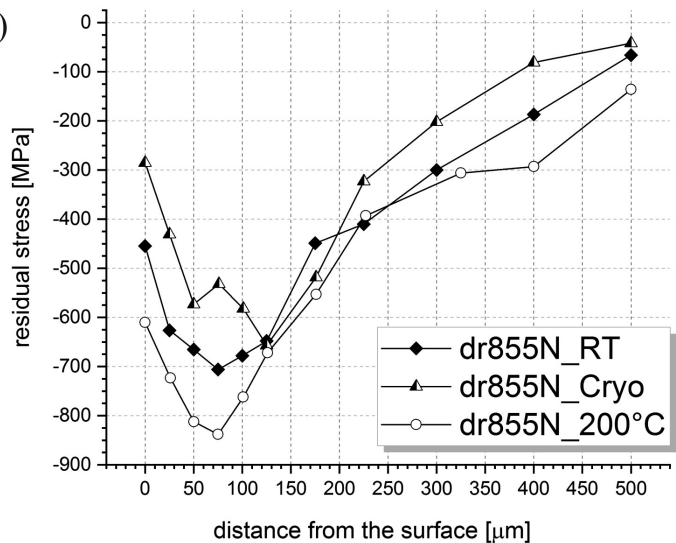

c)

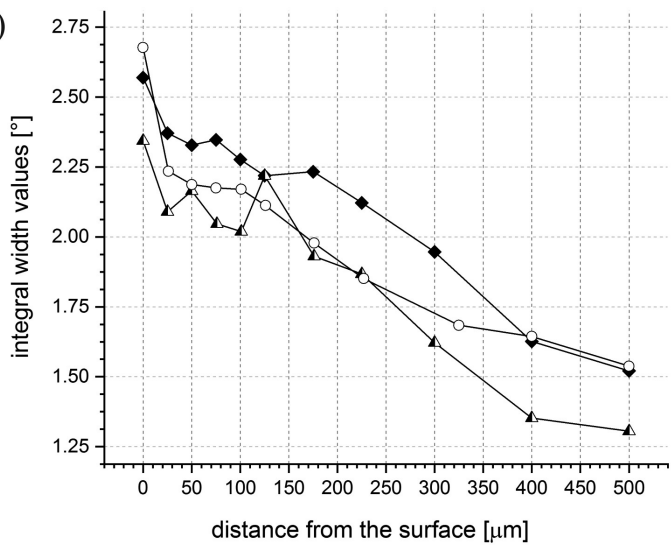

b)

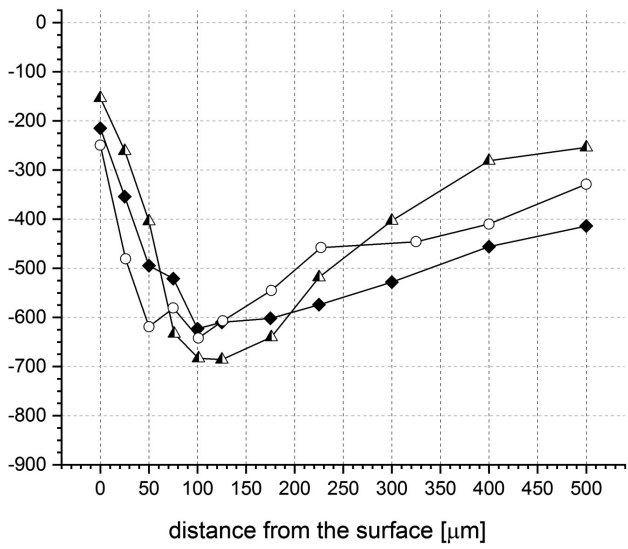

d)

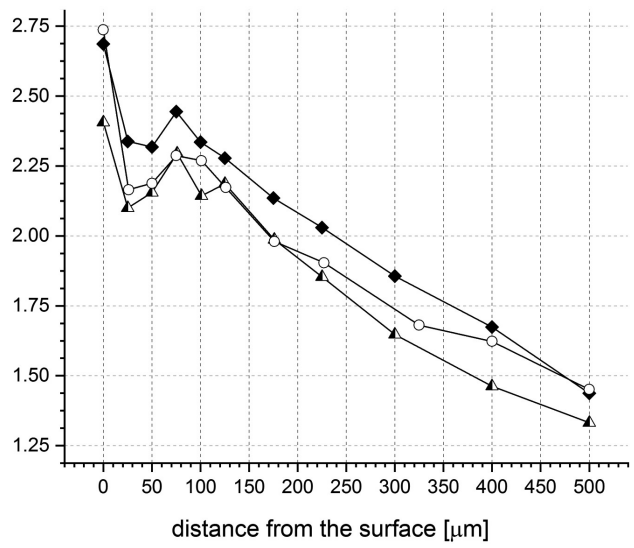

Figure 8. Residual stress profiles and integral width values in longitudinal $(\mathbf{a}+\mathbf{c})$ and circumferential $(\mathbf{b}+\mathbf{d})$ direction plotted as a function of deep rolling temperature at constant deep rolling force. 


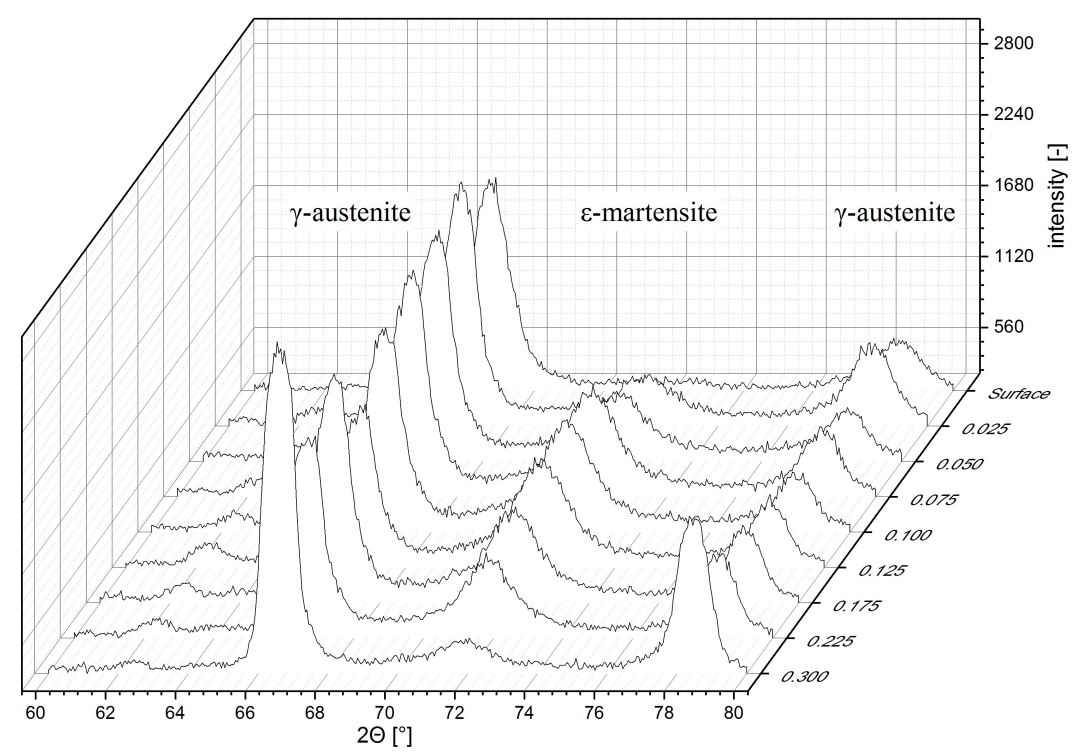

Figure 9. $\mathrm{XRD}$ phase analysis using $C r K \alpha$-radiation revealing a significant martensitic phase fraction upon deep rolling at cryogenic temperature. Peak profiles are plotted as a function of distance from the surface.
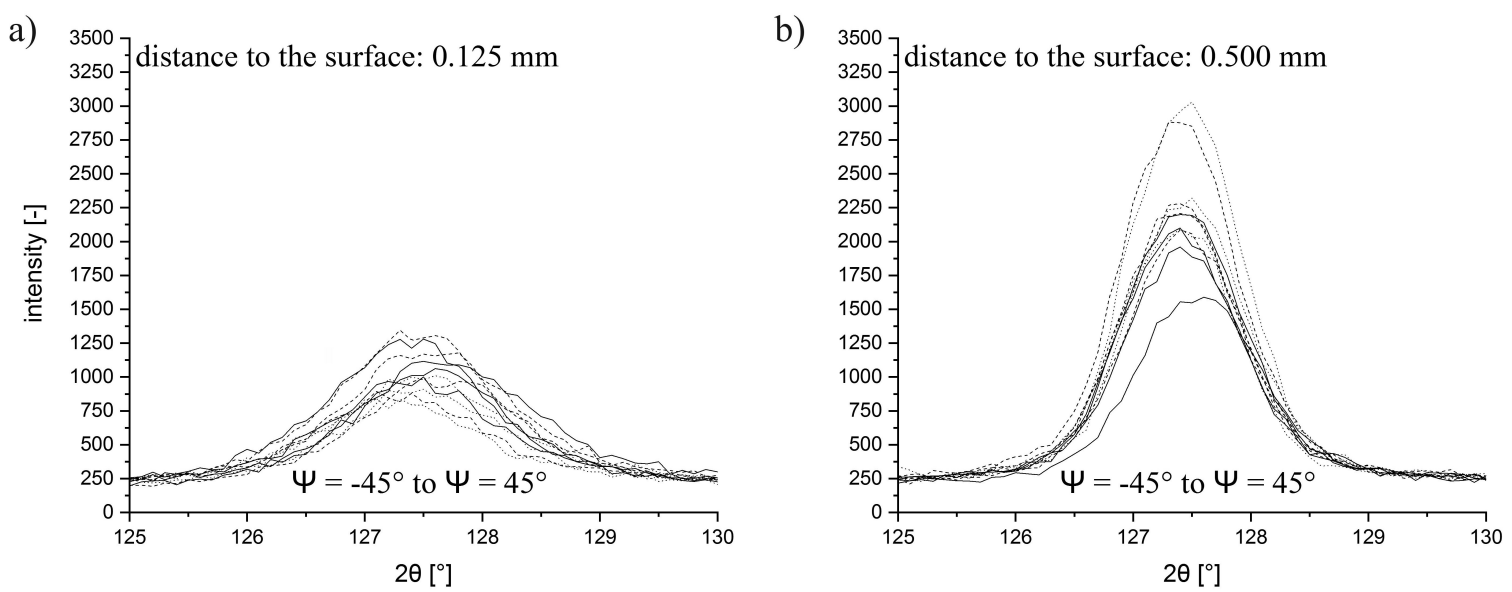

Figure 10. XRD peaks used for determination of residual stresses in a depth of $0.125 \mathrm{~mm}$ (a) and $0.500 \mathrm{~mm}(\mathbf{b})$, respectively, plotted for $\Psi$-angles ranging from $-45^{\circ}$ to $45^{\circ}$.

\subsection{Fatigue Tests}

After thorough characterization of the near surface properties, fatigue tests in the HCF regime were performed considering the conditions deep rolled at $200^{\circ} \mathrm{C}$, room temperature and cryogenic temperature. Taking into account the residual stress depth profiles only, the superior specimen condition was expected to be the condition deep rolled at high temperature. Highest residual stress values in the near surface area and the assumedly higher stability of the residual stresses, as reported in literature for other alloys [33,37], were expected to be the major factors in this regard. The behavior of the condition deep rolled at cryogenic temperature could not be predicted based on literature results, as the consequences of the phase transformation to $\epsilon$-martensite in the near surface area have only been analyzed scarcely so far. However, in light of the lower residual stress level, determined based on the austenitic phase, and the lower hardness level, the number of cycles to failure at a given loading amplitude was expected to be lower. Figure 11 highlights the fatigue lives of all analyzed conditions. Compared to the results of the as-received state, deep rolling at room temperature leads to an increased fatigue life for all load levels, consistent with the current literature reporting on the fatigue properties of room temperature mechanically surface treated TWIP steels [29,30]. At a loading amplitude of 
$460 \mathrm{MPa}$, i.e., the highest level considered for the as-received condition, the average difference of the number of cycles to failure amounts to a factor of about 14. This factor decreases with decreasing loading amplitude to a minimum of about 6 at a loading amplitude of $425 \mathrm{MPa}$. The advantages of deep rolling at elevated temperature known from literature for austenitic steels $[27,38]$ and other steel grades [39] are not yet achieved at the deep rolling temperature of $200^{\circ} \mathrm{C}$ in case of the TWIP steel studied. At relatively high loads, deep rolling at $200^{\circ} \mathrm{C}$ seems to have a positive effect on the fatigue life; however, this has to be analyzed in future studies based on a statistical basis. An absolutely unexpected behavior can be seen for the specimen deep rolled at cryogenic temperature. Hardly any differences can be seen between the deep rolled specimens being characterized by differences in strain hardening, residual stresses or phase transformation with respect to the fatigue life for loading amplitudes below $460 \mathrm{MPa}$. A loading amplitude of $460 \mathrm{MPa}$, however, seems to be a critical loading level, as here significant divergences in terms of trend lines for the different conditions can be derived.

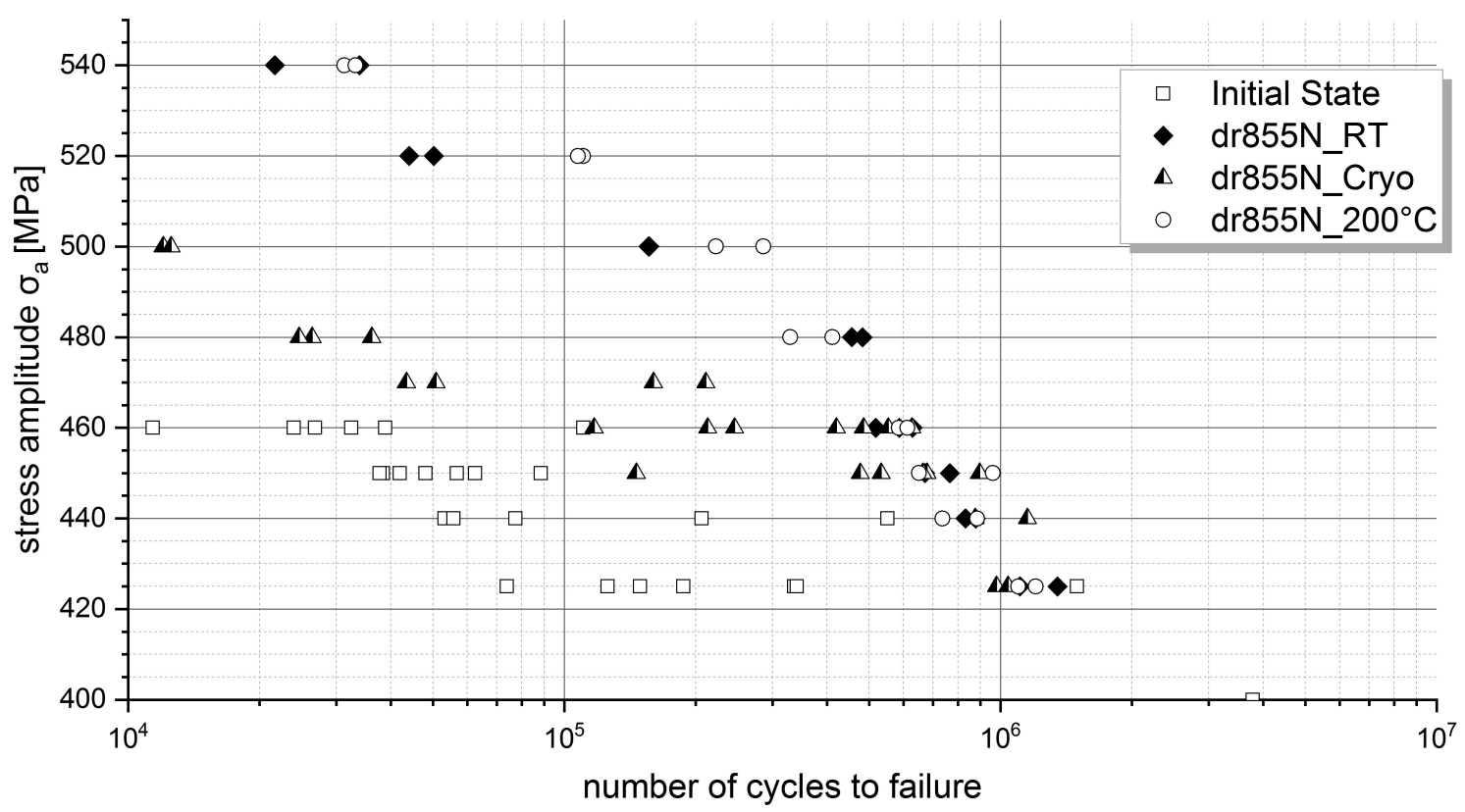

Figure 11. Woehler-type S-N plots for conditions deep rolled at high, room and cryogenic temperature applying a constant deep rolling force of $855 \mathrm{~N}$. See text for details.

Fracture surface analysis reveals that the common advantages of deep rolling known from literature, i.e., the shifting of the point of crack initiation away from the surface to the specimen interior by introducing compressive residual stresses in the near surface layers, can be also seen for the TWIP steel conditions deep rolled at room temperature (cf. Figure 12a)) and $200^{\circ} \mathrm{C}$. (The latter condition is not shown for sake of brevity.) For the cryogenic deep rolled specimens, these well-established relationships seem not to hold true. At a loading amplitude of $480 \mathrm{MPa}$, all specimens deep rolled at cryogenic temperature show crack initiation at the surface, cf. Figure 12b. Consequently, fatigue lives are significantly reduced. A reduction of fatigue life by a factor as large as twenty can be seen. Another critical aspect in evaluating the cryogenic deep rolled condition is the huge scatter seen in the results (between load levels of $480 \mathrm{MPa}$ and $450 \mathrm{MPa}$ ). Specimens characterized by crack initiation below the surface show comparably high numbers of cycles to fracture, approaching the room temperature deep rolled condition, whereas some specimens show premature failure induced by crack initiation close to the surface, Figure 13. These specimens are characterized by numbers of cycles to failure similar to the initial state. This behavior, however, currently seems to be unpredictable and probably is related to the phase fraction of $\epsilon$-martensite in the near surface area and/or the morphology of the martensitic phase (cf. Figure 6d)). How far these factors promote a microstructure notch effect, internal friction, 
local cyclic plasticity and degradation mechanisms related hereto cannot be deduced from current results and, thus, analysis of relationships has to be subject of future work.
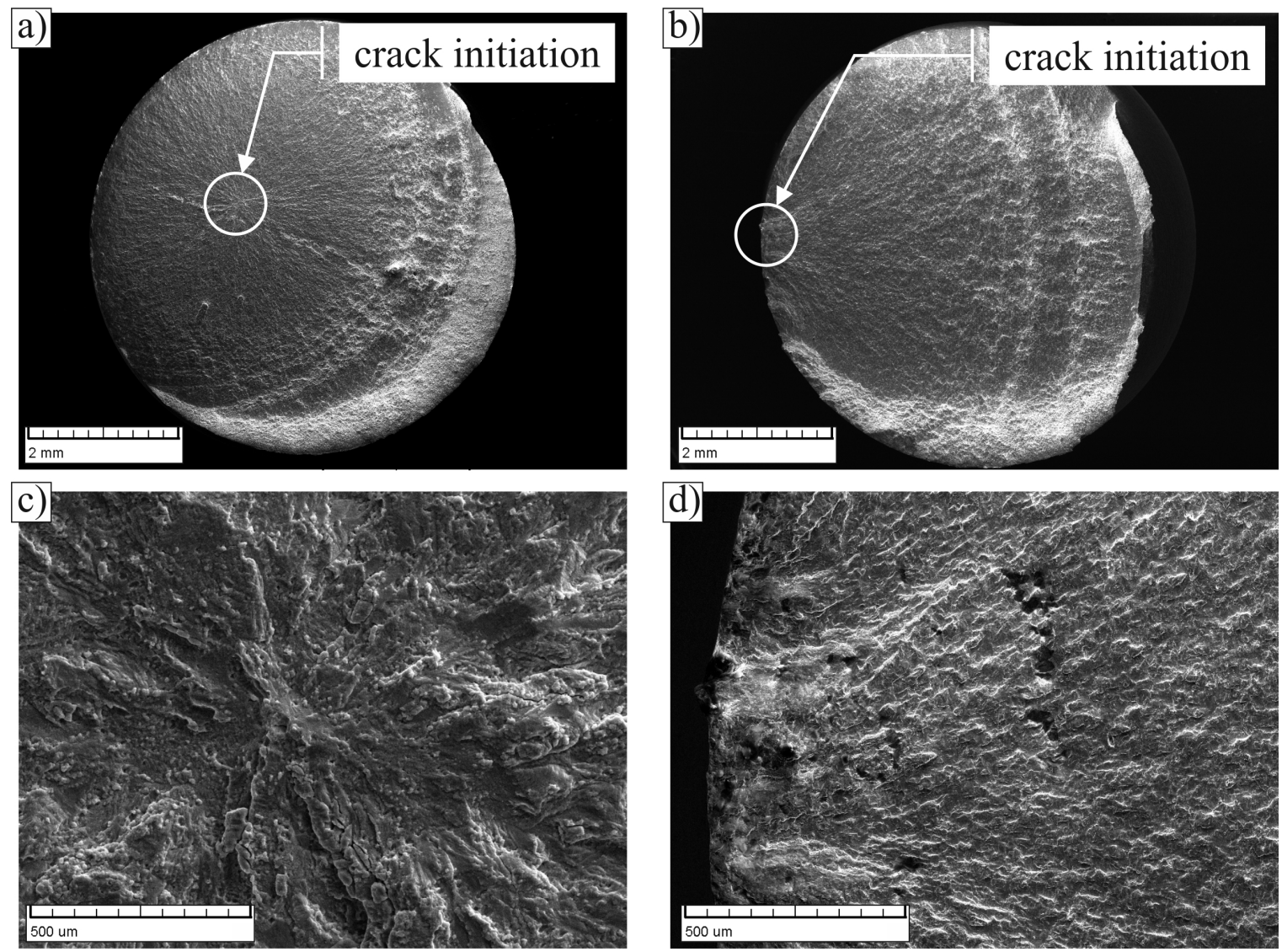

Figure 12. Fracture surfaces of specimen deep rolled at room temperature and cryogenic temperature fatigued at a cyclic loading amplitude of $480 \mathrm{MPa}$. Overview images of conditions deep rolled at room (a) and cryogenic (b) temperature using a deep rolling force of $855 \mathrm{~N}$ are depicted with encircled crack initiation spots. High resolution micrographs depicting the microstructural features being responsible for crack initiation are shown in $(\mathbf{c}+\mathbf{d})$.
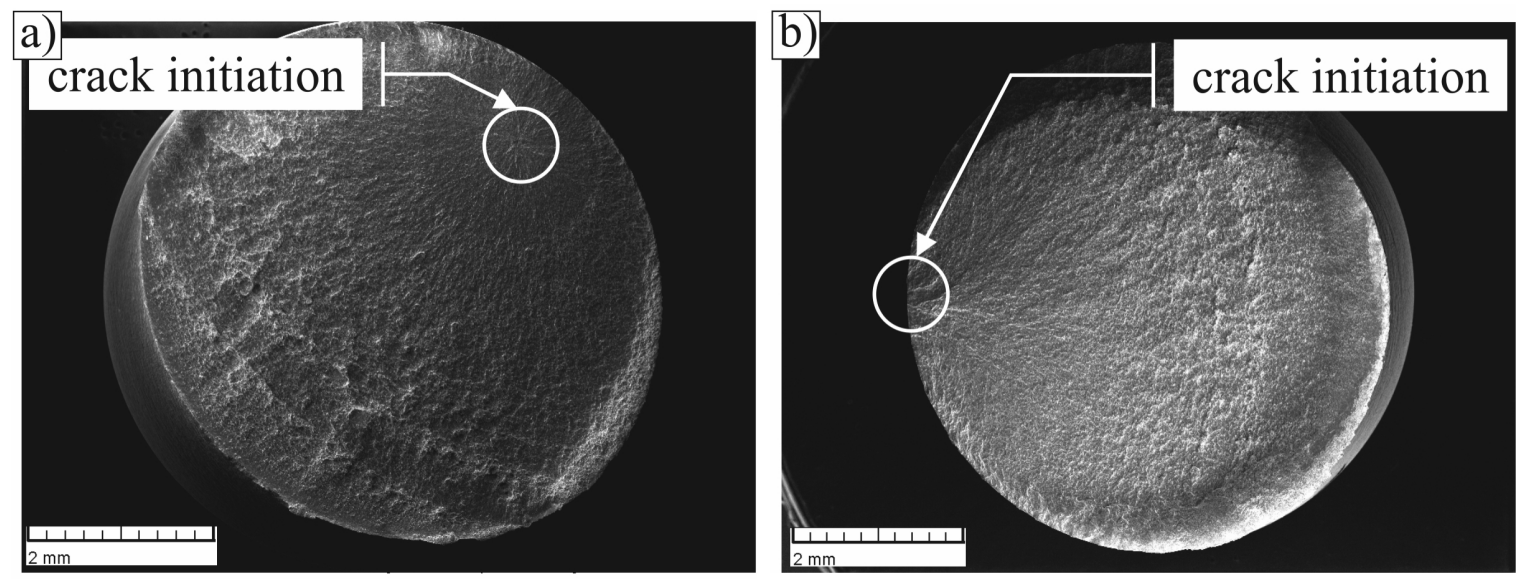

Figure 13. Fracture surfaces of specimens deep rolled at cryogenic temperature after fatigue tests applying a cyclic loading amplitude of $460 \mathrm{MPa}$. The overview SEM micrographs depict the respective crack initiation points. The specimens are characterized by fundamentally different fatigue lives, i.e., 500,000 cycles (a) and 25,000 cycles (b). 


\section{Conclusions}

The present study was conducted to evaluate the influence of deep rolling in a temperature range from $-196^{\circ} \mathrm{C}$ to $200^{\circ} \mathrm{C}$ on the near surface microstructure, hardness distribution and residual stresses of the high-manganese twinning-induced plasticity (TWIP) steel X40MnCrAl19-2 and the related fatigue behavior in the high-cycle fatigue (HCF) regime. The following conclusions can be drawn from the results presented:

- Deep rolling of the TWIP steel improves the monotonic mechanical properties, e.g., the yield strength (from $400 \mathrm{MPa}$ to $550 \mathrm{MPa}$ ), without having any negative effect on the elongation at fracture. Furthermore, high compressive residual stresses with a maximum of $800 \mathrm{MPa}$ are generated in the near surface area accompanied by high hardness values up to 475 HV0.1.

- The martensitic phase transformation promoting $\epsilon$-martensite in the near surface area induced by cryogenic deep rolling has a negative impact on the fatigue performance at least at relatively high loading amplitudes. In addition, an unpredictable behavior caused by random premature crack initiation is found at an intermediate stress level. Reasons are thought to be linked to increased internal friction going along with increased plastic deformation during the fatigue tests and/or notch effects in the two-phase region established in the near surface area.

- Superior performance is seen for the TWIP steel deep rolled at elevated temperature. However, in light of findings being present in literature for alternative steel grades, pathways towards further property optimization for the TWIP steel considered could be derived.

Author Contributions: Conceptualization, T.O.; Funding acquisition, T.W. and T.N.; Methodology, T.O.; Project administration, T.N.; Supervision, T.N.; Visualization, T.O.; Writing—original draft, T.O. and T.W.; Writing-review and editing, T.O. and T.W.; All authors contributed equally to the interpretation of results and writing the final version of the manuscript.

Funding: This research was funded by "Deutsche Forschungsgemeinschaft" (DFG) (German Research Foundation), Grant No. 406320672, within the research project "Mechanische Oberflächenbehandlung von hochmanganhaltigen TWIP/TRIP Stählen-Mikrostrukturelle Stabilität and Mechanische Eigenschaften".

Acknowledgments: The authors would like to thank Rolf Diederich and Rainer Hunke for technical support regarding the maintenance and operation of the laboratory equipment. The assistance of Leoni Hübner is greatly appreciated. The authors acknowledge thyssenkrupp Hohenlimburg GmbH (Hagen, Germany) for providing the material.

Conflicts of Interest: The authors declare no conflict of interest. The funding agency had no influence on the design of the study, the collection, analysis, or interpretation of data, the writing of the manuscript, or the decision to publish the results.

\section{References}

1. Ferreira, P.; Müllner, P. A thermodynamic model for the stacking-fault energy. Acta Mater. 1998, 46, 4479-4484. [CrossRef]

2. Karaman, I.; Sehitoglu, H.; Gall, K.; Chumlyakov, Y.; Maier, H. Deformation of single crystal Hadfield steel by twinning and slip. Acta Mater. 2000, 48, 1345-1359. [CrossRef]

3. Sato, K.; Ichinose, M.; Hirotsu, Y.; Inoue, Y. Effects of deformation induced phase transformation and twinning on the mechanical properties of austenitic Fe-Mn-Al alloys. ISIJ Int. 1989, 29, 868-877. [CrossRef]

4. Grässel, O.; Krüger, L.; Frommeyer, G.; Meyer, L.W. High strength Fe-Mn-(Al, Si) TRIP/TWIP steels development-properties-application. Int. J. Plast. 2000, 16, 1391-1409. [CrossRef]

5. Ishida, K.; Nishizawa, T. Effect of Alloying Elements on the Stability of Epsilon Iron. J. Jpn. Inst. Metals 1972, 36, 1238-1245. [CrossRef]

6. Schramm, R.E.; Reed, R.P. Stacking fault energies of seven commercial austenitic stainless steels. Metall. Trans. A 1975, 6, 1345-1351. [CrossRef]

7. Firrao, D.; Matteis, P.; Scavino, G.; Ubertalli, G.; Pozzi, C.; Ienco, M.G.; Piccardo, P.; Pinasco, M.R.; Costanza, G.; Montanari, R.; et al. Microstructural Effects in Face-Centered-Cubic Alloys after Small Charge Explosions. Metall. Mater. Trans. A 2007, 38, 2869-2884. [CrossRef] 
8. Rüsing, C.; Lambers, H.G.; Lackmann, J.; Frehn, A.; Nagel, M.; Schaper, M.; Maier, H.; Niendorf, T. Property Optimization for TWIP Steels-Effect of Pre-deformation Temperature on Fatigue Properties. Mater. Today Proc. 2015, 2, S681-S685. [CrossRef]

9. Schilke, M.; Ahlström, J.; Karlsson, B. Low cycle fatigue and deformation behaviour of austenitic manganese steel in rolled and in as-cast conditions. Procedia Eng. 2010, 2, 623-628. [CrossRef]

10. Wu, Y.X.; Tang, D.; Jiang, H.T.; Mi, Z.L; Xue, Y.; Wu, H.P. Low Cycle Fatigue Behavior and Deformation Mechanism of TWIP Steel. J. Iron Steel Res. Int. 2014, 21, 352-358. [CrossRef]

11. Shao, C.; Zhang, P.; Liu, R.; Zhang, Z.; Pang, J.; Zhang, Z. Low-cycle and extremely-low-cycle fatigue behaviors of high-Mn austenitic TRIP/TWIP alloys: Property evaluation, damage mechanisms and life prediction. Acta Mater. 2016, 103, 781-795. [CrossRef]

12. Shao, C.; Zhang, P.; Zhu, Y.; Zhang, Z.; Pang, J.; Zhang, Z. Improvement of low-cycle fatigue resistance in TWIP steel by regulating the grain size and distribution. Acta Mater. 2017, 134, 128-142. [CrossRef]

13. Rüsing, C.J.; Niendorf, T.; Frehn, A.; Maier, H.J. Low-Cycle Fatigue Behavior of TWIP Steel - Effect of Grain Size. Adv. Mater. Res. 2014, 891-892, 1603-1608. [CrossRef]

14. Ju, Y.B.; Koyama, M.; Sawaguchi, T.; Tsuzaki, K.; Noguchi, H. Effects of $\epsilon$-martensitic transformation on crack tip deformation, plastic damage accumulation, and slip plane cracking associated with low-cycle fatigue crack growth. Int. J. Fatigue 2017, 103, 533-545. [CrossRef]

15. Nikulin, I.; Sawaguchi, T.; Ogawa, K.; Tsuzaki, K. Effect of $\gamma$ to $\epsilon$ martensitic transformation on low-cycle fatigue behaviour and fatigue microstructure of Fe-15Mn-10Cr-8Ni-x Si austenitic alloys. Acta Mater. 2016, 105, 207-218. [CrossRef]

16. Niendorf, T.; Lotze, C.; Canadinc, D.; Frehn, A.; Maier, H.J. The role of monotonic pre-deformation on the fatigue performance of a high-manganese austenitic TWIP steel. Mater. Sci. Eng. A 2009, 499, 518-524. [CrossRef]

17. Guo, Q.; Chun, Y.S.; Lee, J.H.; Heo, Y.U.; Lee, C.S. Enhanced low-cycle fatigue life by pre-straining in an Fe-17Mn-0.8C twinning induced plasticity steel. Metals Mater. Int. 2014, 20, 1043-1051. [CrossRef]

18. Hamada, A.; Karjalainen, L.; Puustinen, J. Fatigue behavior of high-Mn TWIP steels. Mater. Sci. Eng. A 2009, 517, 68-77. [CrossRef]

19. Hamada, A.; Karjalainen, L.; Ferraiuolo, A.; Sevillano, J.G.; de las Cuevas, F.; Pratolongo, G.; Reis, M. Fatigue Behavior of Four High-Mn Twinning Induced Plasticity Effect Steels. Metall. Mater. Trans. A 2010, 41, 1102-1108. [CrossRef]

20. Hamada, A.; Karjalainen, L. High-cycle fatigue behavior of ultrafine-grained austenitic stainless and TWIP steels. Mater. Sci. Eng. A 2010, 527, 5715-5722. [CrossRef]

21. Song, S.W.; Lee, J.H.; Lee, H.J.; Bae, C.M.; Lee, C.S. Enhancing high-cycle fatigue properties of cold-drawn Fe-Mn-C TWIP steels. Int. J. Fatigue 2016, 85, 57-64. [CrossRef]

22. Niendorf, T.; Klimala, P.; Maier, H.J.; Frehn, A. The Role of Notches on Fatigue Life of TWIP Steel in the HCF Regime. Mater. Sci. Forum 2012, 706-709, 2205-2210. [CrossRef]

23. Shao, C.; Zhang, P.; Wang, X.; Wang, Q.; Zhang, Z. High-cycle fatigue behavior of TWIP steel with graded grains: breaking the rule of mixture. Mater. Res. Lett. 2018, 7, 26-32. [CrossRef]

24. Shao, C.; Wang, Q.; Zhang, P.; Zhu, Y.; Zhao, Z.; Wang, X.; Zhang, Z. Improving the high-cycle fatigue properties of twinning-induced plasticity steel by a novel surface treatment process. Mater. Sci. Eng. A 2019, 740-741, 28-33. [CrossRef]

25. Skorupski, R.; Smaga, M.; Eifler, D. Influence of Surface Morphology on the Fatigue Behavior of Metastable Austenitic Steel. Adv. Mater. Res. 2014, 891-892, 464-469. [CrossRef]

26. Mughrabi, H. Cyclic Slip Irreversibilities and the Evolution of Fatigue Damage. Metall. Mater. Trans. B 2009, 40, 431-453. [CrossRef]

27. Nikitin, I.; Scholtes, B. Deep rolling of austenitic steel AISI 304 at different temperatures-near surface microstructures and fatigue. HTM J. Heat Treat. Mater. 2012, 67, 188-194. [CrossRef]

28. Webster, G.; Ezeilo, A. Residual stress distributions and their influence on fatigue lifetimes. Int. J. Fatigue 2001, 23, 375-383. [CrossRef]

29. Teichmann, C.; Wagner, L. Shot peening of TWIP steel-influence on mechanical properties. In Proceedings of the ICSP-12, Goslar, Germany, 15-18 September 2014.

30. Klein, M.; Smaga, M.; Beck, T. Surface Morphology and Its Influence on Cyclic Deformation Behavior of High-Mn TWIP Steel. Metals 2018, 8, 832. [CrossRef] 
31. Abrão, A.; Denkena, B.; Köhler, J.; Breidenstein, B.; Mörke, T.; Rodrigues, P. The influence of heat treatment and deep rolling on the mechanical properties and integrity of AISI 1060 steel. J. Mater. Proc. Technol. 2014, 214, 3020-3030. [CrossRef]

32. Kloos, K.H.; Adelmann, J. Schwingfestigkeitssteigerung durch Festwalzen. Materialwissenschaft und Werkstofftechnik 1988, 19, 15-23. [CrossRef]

33. Nikitin, I.; Altenberger, I.; Cherif, M.A.; Juijerm, P.; Maier, H.J.; Scholtes, B. Festwalzen bei erhöhten Temperaturen zur Steigerung der Schwingfestigkeit. HTM Härtereitechnische Mitteilungen 2006, 61, 289-295. [CrossRef]

34. Rüsing, C.J. Optimierung der monotonen und zyklischen Eigenschaften von hoch manganhaltigen TWIP-Stählen-Einfluss von Temperatur und Vorverformung auf die Mikrostrukturentwicklung. Ph.D. Thesis, Fakultät für Maschinenbau, Universität Paderborn, Paderborn, Germany, 2015.

35. Cooman, B.C.D.; Estrin, Y.; Kim, S.K. Twinning-induced plasticity (TWIP) steels. Acta Mater. 2018, 142, 283-362. [CrossRef]

36. Kongthep, J.; Timmermann, K.; Scholtes, B.; Niendorf, T. On the impact of deep rolling at different temperatures on the near surface microstructure and residual stress state of steel AISI 304. Materialwissenschaft und Werkstofftechnik 2019, 50, 788-795. [CrossRef]

37. Nikitin, I.; Altenberger, I. Comparison of the fatigue behavior and residual stress stability of laser-shock peened and deep rolled austenitic stainless steel AISI 304 in the temperature range $25-600{ }^{\circ} \mathrm{C}$. Mater. Sci. Eng. A 2007, 465, 176-182. [CrossRef]

38. Nikitin, I.; Altenberger, I.; Scholtes, B. Effect of Deep Rolling at Elevated and Low Temperatures on the Isothermal Fatigue Behavior of AISI 304. Proc. Int. Conf. Shot Peen. 2005, 9, 185-190.

39. Cherif, A.; Scholtes, B. Kombinierte thermische und mechanische Festwalzbehandlungen von gehärtetem und vergütetem Stahl Ck 45. HTM Härtereitechnische Mitteilungen 2008, 63, 155-161. [CrossRef]

(C) 2019 by the authors. Licensee MDPI, Basel, Switzerland. This article is an open access article distributed under the terms and conditions of the Creative Commons Attribution (CC BY) license (http:/ / creativecommons.org/licenses/by/4.0/). 